\title{
Karakteristik Reservoir Berdasarkan Analisis Petrofisik Pada Formasi Baturaja, Lapangan Aulia, Cekungan Jawa Barat Utara
}

\author{
M. Rio Aulia*1 ${ }^{* 1}$ Thomas Triadi Putranto ${ }^{1}$, Reddy Setyawan ${ }^{1}$ \\ ${ }^{1}$ Departemen Teknik Geologi, Fakultas Teknik, Universitas Diponegoro
}

\begin{abstract}
Abstrak
Formasi Baturaja merupakan salah satu formasi penghasil minyak dari Cekungan Jawa Barat Utara. Formasi Baturaja pada Cekungan Jawa Barat Utara ini memiliki keunikan yaitu kondisi batuan yang tergolong tight, namun bisa memproduksi minyak. Lokasi penelitian berada di Lapangan Aulia, Subcekungan Jatibarang. Penelitian ini bertujuan untuk mengetahui variasi litologi secara vertikal, mengetahui lingkungan pengendapan Formasi Baturaja, mendapatkan nilai properti petrofisik dan menentukan kedalaman reservoir yang prospektif. Metode deterministik digunakan dengan pertimbangan lebih cocok pada litologi yang homogen. Data yang digunakan dalam penelitian adalah data dari 6 sumur pemboran. Hasil analisis kualitatif pada semua sumur menunjukkan variasi litologi tersusun dari batugamping dan batugamping sisipan batulempung. Fasies batuan yang terdapat pada Formasi Baturaja berupa packstone dan perselingan packstone - wakckestone hasil pengendapan laut dangkal dengan fasies karbonat yaitu reef crest. Nilai properti petrofisik di Lapangan Aulia memiliki volume shale rata-rata 0,24281 dan nilai rata-rata porositas efektif sebesar 1-6,5\% (porositas buruk). Porositas yang rendah pada batugamping Formasi Baturaja ini diinterpretasikan sebagai dampak dari fluktuasi muka laut dan akibat diagenesis batugamping. Nilai permeabilitas rata-rata adalah $0,0134-$ 2,0452 $\mathrm{mD}($ tight). Lapisan batuan prospek rerata di Lapangan Aulia adalah 5,67 m dengan lapisan paling tebal dijumpai pada RUO 25, yaitu setebal $9 \mathrm{~m}$ di kedalaman 1.846,110 m (TVDSS).
\end{abstract}

Kata kunci: Analisis Kualitatif; Cekungan Jawa Barat Utara; Fasies Karbonat; Formasi Baturaja; Properti Petrofisik.

\begin{abstract}
The Baturaja Formation is one of the oil-producing formations of the North West Java Basin. The Baturaja Formation in the North West Java Basin is unique in that the rock conditions are classified as tight but can produce oil. The research location is in Aulia Field at Jatibarang Subbasin. This study aims to determine the vertical lithology variation, the depositional environment of the Baturaja Formation, to obtain petrophysical property values and the prospective reservoir depth. The data used in the study are drilling data from six drilling well. Determenistic method is conducted considering that it is suitable for relatively homogene rocks. The lithology in Aulia Field consists of limestone and limestone interbedded with claystone. The rock facies in the Baturaja Formation are packstone and the intercalating packstone - wakckestone product of shallow marine, carbonate facies of reef crest. In Aulia Field, the average shale volume is 0.24281 and the average effective porosity is $1-6.5 \%$ (low porosity). Low porosity Baturaja Formation Limestone is interpreted due to the influence of sea level fluctuation and diagenesis. The average permeability value is $0.0134-2.0452 \mathrm{mD}$ which is classified as tight. In Aulia Field, the average thickness of prospect layer is $5.67 \mathrm{~m}$, where the thickest is at RUO 25 with $9 \mathrm{~m}$ thick at 1,846,110 m (TVDSS).
\end{abstract}

Keyword: Qualitative Analisys; North West Java Basin; Carbonate Facies; Baturaja Formation; Petrohpysical Property.

\section{PENDAHULUAN}

Lapangan Aulia yang menjadi daerah penelitian termasuk ke dalam Cekungan Jawa Barat Utara (Gambar 1). Peranan geologist dalam eksplorasi cekungan dan peningkatan produksi minyak dan gas bumi serta keunikan Formasi Baturaja pada
Cekungan Jawa Barat Utara yang tergolong memiliki porositas yang relatif kecil tetapi bisa memproduksi minyak merupakan alasan dilakukannya penelitian di Lapangan Aulia ini. Cekungan Jawa Barat merupakan salah satu

*) Korespondensi: auliamrio@ student.undip.ac.id 
cekungan penghasil hidrokarbon di Indonesia. Secara umum, Cekungan Jawa Barat Utara terletak di barat laut Pulau Jawa dan meluas hingga lepas pantai utara Jawa. Cekungan ini dibatasi oleh Cekungan Arjuna di bagian utara, Cekungan Bogor di bagian selatan, Busur Karimunjawa di bagian timur, Platform Seribu di bagian barat laut Cekungan Jawa Barat terdiri dari beberapa segmen di bagian offshore terdiri dari Platform Seribu, Cekungan Arjuna, dan Cekungan Vera di bagian onshore terdiri dari Tinggian Tangerang, Cekungan Ciputat, Tinggian Rengasdengklok, Cekungan Pasir Putih, Tinggian Pamanukan, dan Cekungan Jatibarang. Cekungan Jawa Barat Utara merupakan system busur belakang (back arc system), berada diantara lempeng Mikro Sunda dan lempeng India-Australia. Pada mulanya, cekungan ini merupakan pull apart basin pada bagian fore arc, setelah mengalami tektonisme dan vulkanisme sejak Kapur Akhir, lokasinya berubah menjadi wilayah back arc (Pertamina, 1996). Cekungan ini dipengaruhi oleh system block faulting berarah utara-selatan. Menurut Koesoemadinata (1980), struktur tersebut menyebabkan cekungan Jawa Barat Utara terbagi menjadi Subcekungan Jatibarang, Subcekungan Pasir Putih, Subcekungan Ciputat, Subcekungan Arjuna (lepas pantai). Tiap Subcekungan dipisahkan oleh tinggian berupa blok naik dari sesar (Pertamina, 1996). Tinggian Rengasdengklok memisahkan Sub-Cekungan Ciputat dan Pasir Putih, Tinggian Pamanukan dan Kadanghaur memisahkan Subcekungan Pasir Putih dan Jatibarang.
Penelitian dilakukan pada Lapangan Aulia, Cekungan Jawa Barat Utara. Lapangan Aulia terletak sebelah timur dari Cekungan Jawa Barat Utara dan termasuk ke dalam Subcekungan Jatibarang. Penelitian ini dilakukan pada lapangan Aulia karena pada lapangan ini reservoir yang terdapat pada lapangan Aulia ini merupukan batugamping dengan porositas yang tergolong ketat tetapi masih bisa memproduksi minyak dalam jumlah yang besar. Penelitian ini bertujuan untuk mengetahui variasi litologi berdasarkan analisis kualitatif, mengetahui lingkungan pengendapan berdasarkan dari analisis elektrofasies pada Formasi Baturaja, mengetahui nilai properti petrofisik pada Formasi Baturaja dan pay summary terkait dengan karakteristik reservoir.

\section{Stratigrafi Regional}

Stratigrafi regional Cekungan Jawa Barat Utara dari tua ke muda tersusun dari batuan dasar, Formasi Jatibarang, Formasi Talang Akar, Formasi Baturaja, Formasi Cibulakan Atas, Formasi Parigi, Formasi Cisubuh dan Endapan Kuarter (Wahab dan Martono, 1985). Penelitian dilakukan pada interval Formasi Baturaja (Gambar 2). Adapun satuan batuan yang terdapat pada Formasi Baturaja antara lain batugamping terumbu yang umumnya dijumpai pada daerah tinggian, selain itu juga ditemukan dolomit, serpih, glaukonit, napal dan chert. Pada Formasi Baturaja ini terdapat juga fosil Foraminifera Spiroclypens $S p$ yang melimpah (Wahab dan Martono, 1985).

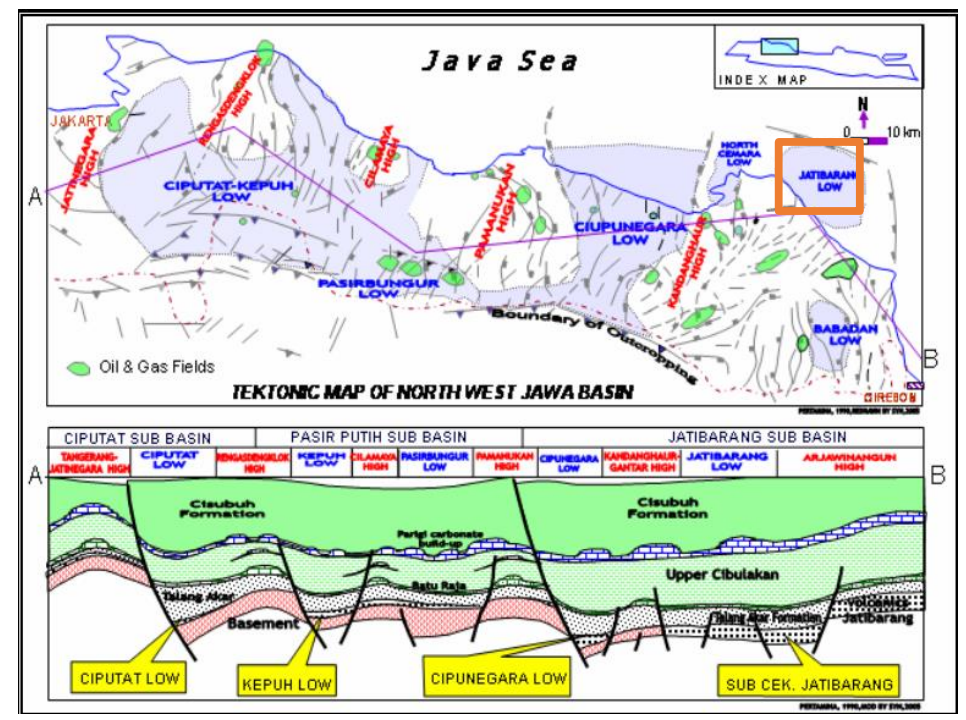

Gambar 1. Lapangan Aulia (ditandai kotak merah) di Cekungan Jawa Barat Utara (Pertamina, 1996). 


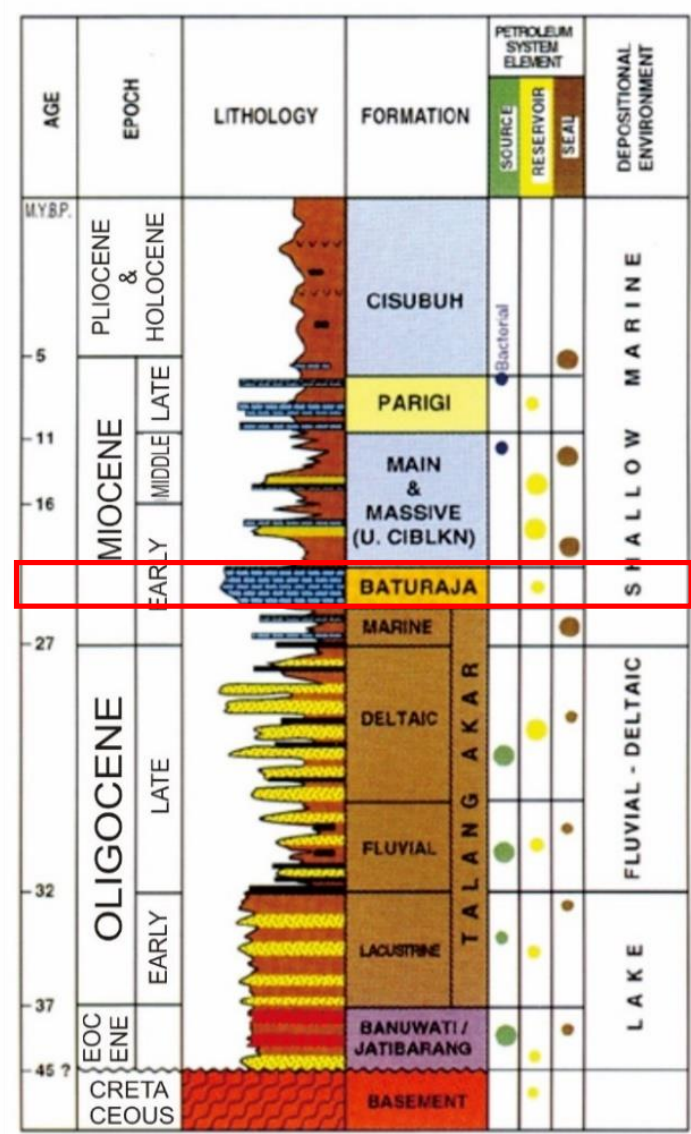

Gambar 2. Stratigrafi Cekungan Jawa Barat Utara, kotak merah adalah interval yang diteliti pada Lapangan Aulia (Noble,dkk., 1997).

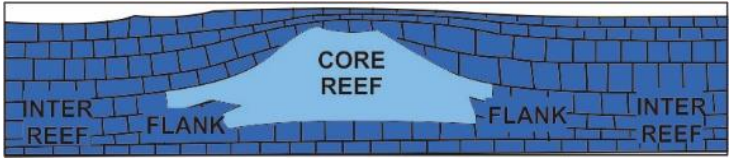

Gambar 3. Fasies Terumbu (James dan Macyntire, 1980)

\section{Batuan Karbonat}

Batuan Karbonat adalah batuan yang terdiri dari fraksi karbonat yang lebih dominan dibandingkan dengan fraksi non karbonat atau dengan kata lain komposisi fraksi karbonat > 50\% (Pettijohn, 1975 ). Pada umumnya, mineral karbonat adalah Kalsit $\left(\mathrm{CaCO}_{3}\right)$, Dolomit $\left(\mathrm{CaMg}\left(\mathrm{CO}_{3}\right)_{2}\right)$ dan Aragonit. Dalam proses pembentukkannya, batuan karbonat mengalami proses diagenesis agar komponen batuan lebih stabil. Adapun proses diagenesis batuan karbonat terdiri dari proses pelarutan, sementasi, dolomitisasi, dan kompaksi. Batuan karbonat dapat tumbuh dengan baik dengan syarat yaitu dengan terbentuk pada suhu yang hangat, terkena sinar matahari untuk fotosintesis alga yang berperan sebagai penghasil makanan dan kondisis air yang jernih dengan suplai sedimen yang rendah serta kondisi muka air laut.

\section{Fasies Karbonat}

Tipe pertumbuhan terumbu yang utama dibagi menjadi tiga yaitu skeletal (frame-bulit) reefs, reef mounds, dan reef complex (Tucker dan Wright, 1992). Skeletal (frame-built) merupakan pertumbuhan terumbu yang dihasilkan oleh organisme yang hidupnya berkoloni metazoa yang rigid dan mampu menghasilkan relief yang tinggi serta material kalkareus. Keberadaan fasies ini didukung dengan adanya in situ framework yang tahan terhadap gelombang, tetapi tergantung pada morfologi organisme penyusunnya. Pada terumbu modern berupa barries reef complex dan patch reef (James dan Macyntire 1980) (Gambar 3).

\section{a. Reef Core}

Fasies ini merupakan bagian inti dari terumbu yang rigid dengan terdiri dari karang yang tumbuh dengan baik. Selain itu terdiri dari kerangka organik intertestial yang tersusun oleh lumpur. Beberapa daerah akan dijumpai packstone yang memiliki campuran koral skeletal dijumpai di lingkungan mikro antara reef wall atau reef top.

b. Reef Flank

Fasies ini merupakan hasil endapan lereng sedimen karang yang berada disekeliling core, terdiri dari pecahan - pecahan karang di sisi dari reef crest yang disebut sebagai reef sediment slope. Endapan pada fasies ini saling menjadi dengan endapan yang ada pada reef core dan secara lokal dapat ditemukan fasies core apabila fasies tersebut mengalami pertumbuhan secara lateral.

c. Inter - reef deposite

Fasies ini merupakan endapan sedimen di antara pertumbuhan terumbu. Fasies ini memiliki kurang dari $10 \%$ material karbonat dan didominasi oleh material berukuran halus seperti lanau dan lempung.

\section{Lingkungan Pengendapan}

Salah satu data yang dibutuhkan dalam penentuan lingkungan pengendapan adalah dengan memanfaatkan analisis elektrofasies. Analisis elektrofaseis merupakan suatu analisis lingkungan pengendapan berdasarkan 


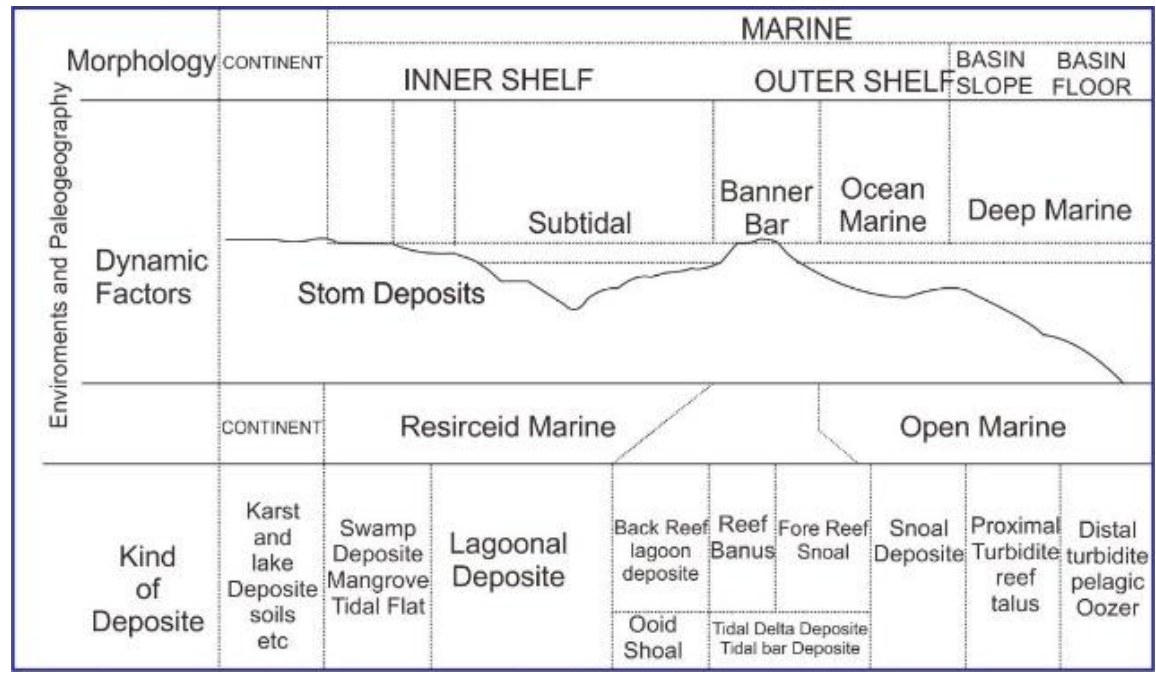

Gambar 4. Lingkungan Pengendapan Batuan Karbonat (Friedman dan Reeckmann, 1982).

pola log gamma ray (Walker dan James, 1992). Penentuan lingkungan pengendapan juga didukung dengan data pengamatan petrografi sebagai data pendukung dalam penentuan lingkungan pengendapan. Lingkungan pengendapan didefinisikan sebagai kondisi geografik yang ada pada saat sedimen terakumulasi (Reeckmann,1982).

Batuan sedimen digolongkan sebagai kelompok yang mempunyai parameter biologi, fisika dan kimia sendiri. Interaksi dari parameter di atas menghasilkan perbedaan tipe sedimen atau fasies. Lingkungan pengendapan dapat dibagi menjadi 2 jenis, yaitu marine dan non marine dimana keduanya dipisahkan oleh shoreline (garis pantai). Sedimen dari lingkungan non marine secara umum sangat dipengaruhi oleh meteoric water dan kondisi tersebut akan menyebabkan terjadinya diagenesa lanjut. Lingkungan marine dapat dikelompokkan ke dalam subdivisi menjadi shelf, basin slope dan deep ocean basin. Kedalaman air dari lingkungan shelf berkisar antara $0-200 \mathrm{~m}$. Break of slope membatasi lingkungan shelf dari deep ocean basin yang kedalamannya bisa mencapai lebih dari $1000 \mathrm{~m}$.

Lingkungan shelf dapat dikelompokkan lagi menjadi beberapa subdivisi berdasarkan karakteristik morfologi, sirkulasi air, salinitas, dan daya tembus cahaya. Variasi dan interaksi dari komponen tersebut adalah sebagai pengontrol pertumbuhan karbonat pada lingkungan shelf (Friedman dan Reeckmann, 1982). Lingkungan shelf dibagi menjadi inner shelf yang lebih dekat dengan kontinen dan outer shelf yang lebih dekat dengan basin. Beberapa fasies pengendapan pada lingkungan ini antara lain, fasies supratidal dan intertidal atau fasies tidal flat, fasies subtidal atau fasies lagoonal, fasies barrier reef terdiri dari fasies back reef, fasies reef bank dan fasies fore reef ( Gambar 4).

\section{Petrofisik}

Petrofisik adalah ilmu yang mempelajari tentang sifat fisik dan kimia dari batuan dan fluida yang ada di dalamnya yang berdasarkan perhitungan, rekaman sumur, data lab, serta hukum dasar dari matematika dan fisika. Parameter petrofisik bisa ditentukan secara langsung melalui sampel batuan hasil inti bor maupun dari hasil rekaman sumur. Parameter utamanya adalah porositas, permeabilitas, kejenuhan air, dan resistivitas (Asquith dkk, 1982).

\section{a. Volume Shale}

Volume shale merupakan presentase dari kandungan serpih pada reservoir. Shale lebih radioaktif daripada batupasir maupun karbonat, rekaman gamma ray digunakan untuk menghitung volume shale dari reservoir. Kehadiran serpih di dalam batuan sedimen menyebabkan terjadinya penyimpangan interpretasi rekaman bila menggunakan rumus untuk batuan bersih (Persamaan 1 dan 2).

$$
\begin{gathered}
\mathrm{IGR}=\frac{G R \log -G R \text { Min }}{G R M a x-G R M i n} \\
\mathrm{Vsh}=\mathrm{IGR}=\frac{\text { GR Log-GRMin }}{\text { GR Max-GRMin }}(2)
\end{gathered}
$$

Keterangan :

GR Log : Gamma Ray pada Log

GR Min : Gamma Ray Minimum

GR Max: Gamma Ray Maksimum 


\section{b. Porositas}

Porositas adalah pebandingan antara volume pori-pori dengan volume total batuan. Pori-pori secara primer adalah matrix pore, dan secara sekunder adalah rekahan/fracture, rongga/vug, dan lain-lain. Pada umumnya, porositas yang terukur, baik secara analisis laboratorium, maupun dengan rekaman adalah porositas efektif. Hal ini karena adanya isolated pore yang tidak berpengaruh terhadap produktivitas reservoir. Berdasarkan sifat batuan reservoir maka porositas dibagi menjadi dua, yaitu porositas efektif dan porositas absolut. Porositas efektif yaitu perbandingan volume pori-pori yang saling berhubungan terhadap volume batuan secara keseluruhan dan dapat mengalirkan fluida. Porositas absolute adalah perbandingan volume pori-pori total tanpa memandang saling berhubungan atau tidak, terhadap volume batuan secara keseluruhan. Sedangkan berdasarkan klasifikasi georekamani porositas dibagi menjadi dua, yaitu porositas primer dan porositas sekunder Persamaan 3 dan 4.

$$
\begin{gathered}
\Phi \mathrm{t}=\frac{\rho m a-\rho l o g}{\rho m a-\rho f l}-\mathrm{Vsh} * \frac{\rho m a-P H I T s h}{\rho m a-\rho f l} \\
\Phi \mathrm{e}=\Phi \mathrm{t}(1-\mathrm{Vsh})(4)
\end{gathered}
$$

Keterangan :

$\begin{array}{ll}\Phi t & \text { : Porositas Total } \\ \Phi \mathrm{e} & \text { : Porositas Efektif } \\ \text { Vsh } & \text { : Volume Shale } \\ \text { plog } & \text { : Nilai densitas pada log } \\ \text { pma } & \text { : Nilai densitas matriks } \\ \text { pfl } & \text { : Nilai densitas fluida }\end{array}$

PHITsh :Porositas total shale

\section{c. Kejenuhan Air (Sw)}

Saturasi air adalah perbandingan antara volume pori yang ditempati oleh fluida (oil, water, gas) dengan volume pori total dalam batuan. Berdasarkan fluida pengisi rongga batuan reservoir, maka ada tiga jenis saturasi, yaitu saturasi air (Sw), saturasi minyak (So), dan saturasi gas $(\mathrm{Sg})$. Saturasi atau kejenuhan air formasi adalah rasio dari volume pori yang terisi oleh air dengan volume porositas total (Harsono, 1997). Tujuan menentukan saturasi air yaitu untuk menentukan zona yang mengandung hidrokarbon. Jika air merupakan satu-satunya fluida yang ada di dalam poripori batuan, maka nilai $\mathrm{Sw}=1$, tetapi apabila pori-pori batuan terdapat fluida hidrokarbon maka $\mathrm{Sw}<1$. Perhitungan saturasi air ada beberapa metode diantaranya adalah metode Archi persamaan , metode Simandoux (Persamaan 5) dan metode Indonesia (Persamaan 6)

$$
\begin{gathered}
\mathrm{S}_{\mathrm{W}}=\left[\left[\frac{\left(1 / \mathrm{R}_{\mathrm{t}}\right)^{0.5}}{\left[\frac{\left.\mathrm{V}_{\mathrm{sh}}\left(1-\mathrm{V}_{\mathrm{sh} / 2}\right)\right]+\left[\frac{(\phi \mathrm{cm})^{0.5}}{\mathrm{a} \times \mathrm{R}_{\mathrm{W}}}\right]}{\mathrm{R}_{\mathrm{sh}} 0.5}\right]}\right]^{2}\right]^{\frac{1}{\mathrm{n}}} \\
\mathrm{S}_{\mathrm{W}}=\frac{\mathrm{c} \cdot \mathrm{R}_{\mathrm{W}}}{\phi_{c}^{2}}\left[\sqrt{\frac{5 \phi_{\mathrm{e}}{ }^{2}}{\mathrm{R}_{\mathrm{W}} \cdot \mathrm{R}_{\mathrm{t}}}+\left(\frac{\mathrm{V}_{\mathrm{sh}}}{\mathrm{R}_{\mathrm{sh}}}\right)^{2}}-\frac{\mathrm{V}_{\mathrm{sh}}}{\mathrm{R}_{\mathrm{sh}}}\right]
\end{gathered}
$$

Keterangan :

$\begin{array}{ll}\mathrm{Sw} & \text { : Saturasi air } \\ \mathrm{R}_{\mathrm{t}} & \text { : Resistivitas } \\ \mathrm{Vsh} & \text { : Volume shale } \\ \mathrm{Rsh} & \text { : Resistivitas shale } \\ \mathrm{Rw} & \text { : Resistivitas air } \\ \mathrm{a} & \text { : Faktor toursity } \\ \mathrm{m} & \text { : Faktor sementasi } \\ \phi \mathrm{e} & \text { : Porositas efektif }\end{array}$

d. Permeabilitas

Permeabilitas merupakan sifat dari media porous yang mampu mengalirkan fluida akibat perbedaan tekanan di dalamnya (Koesoemadinata, 1980). Permeabilitas ini dinyatakan dalam satuan Darcy, dimana adalah permeabilitas yang memungkinkan fluida dengan viskositas satu centipoise dapat melewatkan sebanyak satu centimeter kubik selama satu detik melalui permukaan seluas satu centimeter persegi. Satuan Darcy dianggap terlalu besar sehingga digunakan satuan miliDarcy $(\mathrm{mD})$. Batuan dikatakan permeabel bila mempunyai porositas yang saling berhubungan misalnya pori-pori, vugs, kapiler, retakan, dan rekahan. Porositas besar sering memberikan permeabilitas besar akan tetapi hal ini tidak selalu benar. Dalam perhitungan permeabilitas metode yang dipakai adalah metode Coates - Dumoir (persamaan 7).

$$
\mathrm{K}=\left\{70 \frac{\Phi e^{2}(1-\text { Swirr })}{\text { Swirr }}\right\}^{2} \text { (7) }
$$

Keterangan :

$$
\begin{array}{ll}
\mathrm{K} & \text { : Permeabilitas } \\
\phi \mathrm{e} & \text { : Porositas efektif } \\
\text { Swirr } & \text { : Air yang tersisa dalam pori }
\end{array}
$$




\section{METODOLOGI}

Penelitian dilakukan dengan menggunakan metode analisis kualitatif dan kuantitatif. Pada analisis kualitatif bertujuan untuk mengetahui jenis litologi yang terdapat pada daerah penelitian. Analisis yang dilakukan dengan memperhatikan pola log (log gamma ray, log resistivitas, log neutron dan densitas) yang ada pada 6 sumur (RUO 25, RUO 27, RUO 28, RUO 31, RUO 33 dan RUO 37). Determinasi litologi juga didukung data mudlog dan data petrografi. Batuan karbonat yang dianalisis petrolgrafi diklasifikasikan menggunakan klasifikasi Sibley dan Gregg (1987).

Analisis kuantitatif bertujuan untuk mendapatkan nilai properti petrofisik, dilakukan dengan menghitung pembacaan nilai log pada setiap sumur. Hasil analisis kuantitatif kemudian akan menjadi input untuk metode deterministik. Vaiasi litologi penyusun daerah penelitian relatif bersifat homogen sehingga tepat jika diaplikasikan metode deterministik. Tahapan pada penelitian ini dijelaskan pada Gambar 5.

\section{HASIL}

\section{Determinasi Litologi}

Sumur RUO 25 memiliki nilai gamma ray 0 - 60 GAPI tergolong rendah, resistivitas antara 350 $400 \Omega \mathrm{m}$ dan densitas yang memiliki nilai $2,0-$ $2,7 \mathrm{gr} / \mathrm{cc}$, namun ada dibeberapa kedalaman pada sumur RUO 25 memiliki nilai gamma ray yang tinggi berkisar 60 - 65 GAPI (Gambar 6). Jika disebandingkan dengan mudlog (Gambar 7), dapat diinterpretasikan bahwa pada sumur ini terdiri dari batugamping dan batulempung.

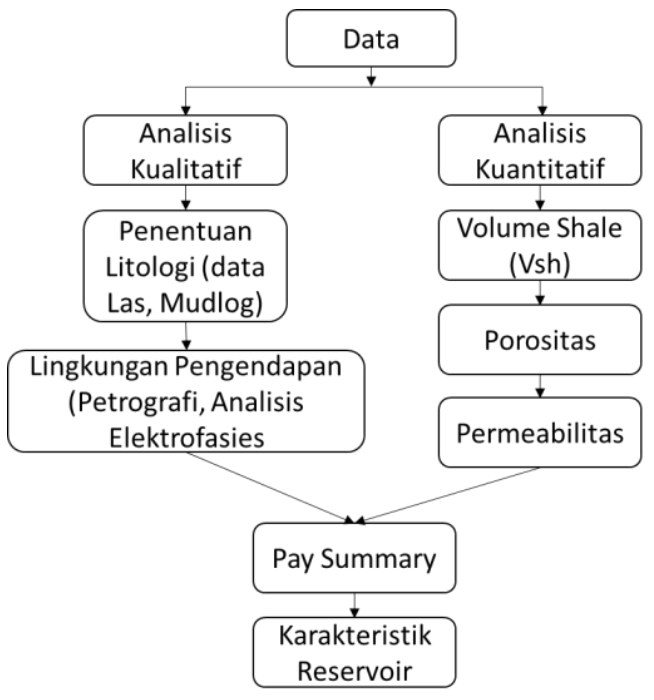

Gambar 5 Diagram Alir
Identifikasi zona reservoir dilakukan dengan melihat log neutron dan log densitas. Zona reservoir biasanya dicirikan oleh litologi yang berbutir kasar (baik itu sandstone ataupun limestone). Selain itu zona reservoir yang terlihat dengan nilai neutron yang rendah dan densitas yang tinggi, kedua log tersebut akan membentuk cross over, semakin besar separasi cross over yang ditunjukkan oleh log densitas dan log neutron dapat ditafsirkan terdapat kandungan hidrokarbon berupa gas pada RUO 25 terdapat cross over di kedalaman $1.050-1.060 \mathrm{~m}$. Apabila separasinya semakin kecil maka kemungkinan kandungannya adalah minyak atau air. Namun dalam penentuan kandungan hidrokarbon berdasarkan dari separasi cross over $\log$ densitas dan neutron tidak terlalu tepat, hal yang diperhatikan adalah pembacaan pada log resistivitas.

Pembacaan nilai log resistivitas merupakan tahapan untuk mengetahui jenis dan tipe fluida. Nilai resistivitas didapatkan dari tahanan jenis, sehingga dari nilai tersebut didapatkan perbedaan karakteristik jenis fluida. Jenis fluida pada zona reservoir dapat berupa air formasi dan hidrokarbon (minyak dan gas bumi). Kandungan air ditandai dengan pembacaan nilai resistivitas yang rendah. Pembacaan nilai resisitivitas untuk gas dan minyak ditandai dengan nilai resistivitas yang tinggi. Pada sumur RUO 25 di kedalaman $1.050 \mathrm{~m}-1.060 \mathrm{~m}$ terdapat kandungan hidrokarbon.

\section{Analisis Petrografi}

Data petrografi yang hanya tersedia pada sumur RUO 31 di kedalaman $1.927 \mathrm{~m}, 1.927,6 \mathrm{~m}$, 1.928,3 m 1.929,3 m, 1.929,6 m. Pada kedalaman $1.927 \mathrm{~m}$ dominan dijumpai dolomit sehingga sulit untuk mengetahui tekstur batuan. Keberadaan dolomit (Gambar 8a) menandakan bahwa batuan pada kedalaman ini telah mengalami diagenesis lanjut. Sayatan tipis pada kenampakkan polarisasi sejajar berwarna merah muda, colorless, biru kehijauan dan coklat, grain supported, serta memiliki tipe pori utama intercrystalline dan vuggy dibeberapa tempat, diinterpretasikan sebagai polymodal planar dolomite with mimically foram bentonic and nonmimically pelecypod (Sibley dan Gregg, 1987).

Batuan tersusun atas butiran mineral kalsit, dolomit ferroan, dolomit sedangkan komposisi butiran skeletal terdapat foraminifera, 


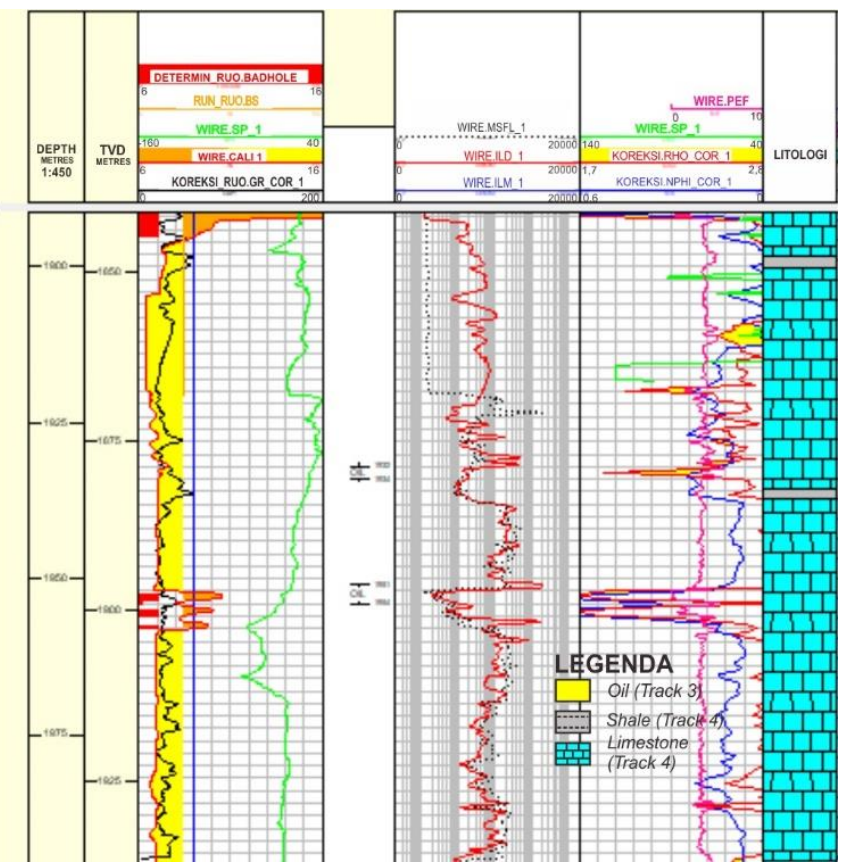

Gambar 6. Hasil Analisis Kualitatif Penentuan Jenis Litologi Sumur RUO 27 dengan Memanfaatkan Log Triple combo (Log litologi, Resistivitas, Neutron Densitas )

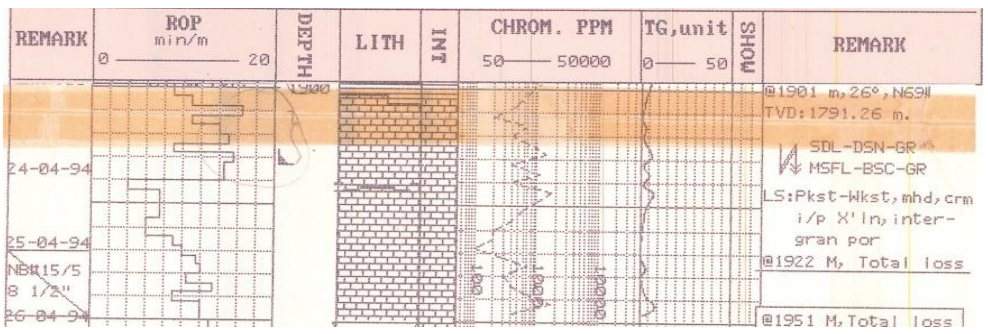

Gambar 7. Mudlog Pada Sumur RUO 27 terdapat Batugamping dan Batulempung pada Pembacaanya

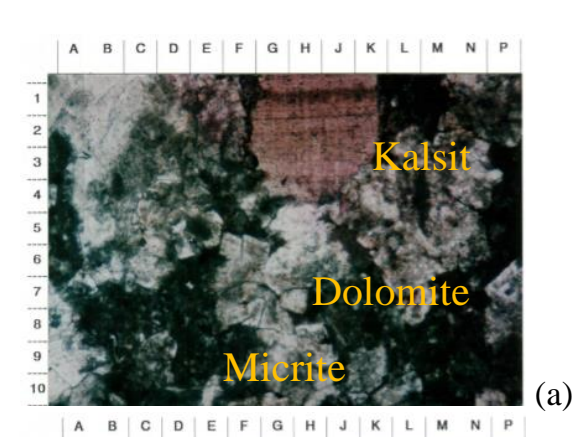
Pertamina)

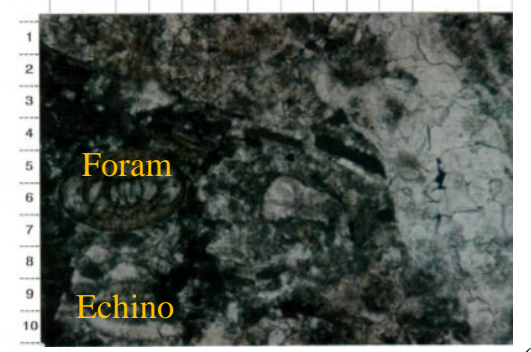

(b)

Gambar 8. Kenampakkan Petrografi Polymodal Planar Dolomite with Mimically Foram Bentonic and Nonmimically Pelecypod Pada Kedalaman 1.927 m. (a) PPL 30 x. (b) XPL 30 (Report Core Analysis PT

pelecypoda, echinodermata (Gambar 8b), bioklastik yang tak teridentifikasi, dan juga terdapat sedikit mikrit. Butiran dan mikrit nampak telah banyak teralterasi menjadi mineral dolomit akibat proses dolomitisasi, sehingga tekstur awal pada batuan sulit untuk diamati.

b. Kedalaman $1.927,3 \mathrm{~m}$

Sayatan pada kedalaman ini memiliki batuan berupa unimodal planar dolomit (Sibley dan Gregg, 1997). Sayatan tipis batuan ini memiliki kenampakkan pada polarisasi sejajar dan menyilang dengan warna colorless, biru kehijauan dan coklat Gambar 9. Pada sayatan ini didominasi oleh butiran (grain supported) serta memiliki pori intercrystalline. Komposisi batuan berupa clay karbonat berupa mikrit, dolomit dan butiran skeletal yang tidak dapat teridentifikasi. Selain itu pada batuan ini juga telah mengalami replacement yang menyebabkan tekstur awal dari batuan ini tidak dapat diidentifikasi. Petrografi 
pada kedalaman 1.928,3 m, 1.929,3 m, dan $1.929,6 \mathrm{~m}$ relatif sama dengan kedalaman 1.927,3 $\mathrm{m}$.

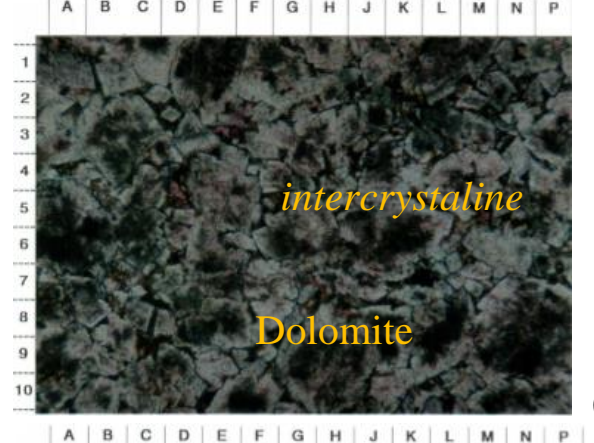

(a)

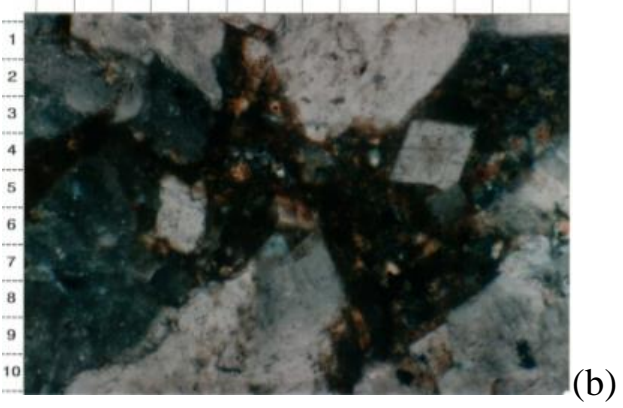

Gambar 9 Kenampakkan Petrografi Unimodal Planar Dolomite (Sibley dan Gregg, 1997) Pada Kedalaman 1.927,3 (Report Core Analysis PT Pertamina).

Analisis petrografi pada sumur RUO 31 ini menunjukkan batuan yaitu berupa grain supported yang didominasi oleh mineral dolomit dan beberapa mineral lainnya. Berdasarkan dari analisis petrografi ini didapatkan porositas berupa intercrystalline sampai vuggy berdasarkan hal tersebut diketahui zona diagenesis pada batuan ini adalah marine freatik, zona percampuran (mixing), zona meteoric vadose, zona burial (Longman, 1980 dalam Tucker dan Wright, 1990). Zona marine phreatic pada zona ini ditandai dengan lingkungan dengan sirkulasi air sedikit yang dicirikan oleh kehadiran mikritisasi. Mikritisasi ini dijumpai pada kedalaman $1.927 \mathrm{~m}$. Kemudian pada zona mixing merupakan percampuran lingkungan freshwaater phreatic dan freshwater vadose dengan karakteristik adanya air payau dan bersifat diam. Pada zona ini ditandai dengan adanya proses dolomitisasi pada analisis petrografi yang telah dilakukan bahwa pada kedalaman 1.927 $1.929,6 \mathrm{~m}$ batuannya telah mengalami proses dolomitisasi, sehingga termasuk kedalam lingkungan diagenesis zona mixing. Tahapan selanjutnya adalah batuan mengalami diagenesis pada zona meteoric vadose hal ini ditandai dengan adanya pelarutan yang menghasilkan porositas sekunder berupa vuggy.

\section{Lingkungan Pengendapan}

Analisis lingkungan pengenapan ini didasarkan pada analisis elektrofasies dengan memperhatikan pola log gamma ray berdasarkan klasifikasi Kendall dan Schlager 1981. Berdasarkan dari analisis elektrofasies pada sumur RUO 31 dimana terdapat dua pola gamma ray seperti terlihat pada Gambar 8. Pola gamma ray dengan bentuk blocky yang mempresentasikan bahwa memiliki stacking pattern berupa aggrading yang menandakan keep up carbonates. Hal ini menandakan bahwa pertumbuhan karbonat dapat tumbuh menyamai dengan muka air laut. Kemudian pada sumur RUO 31 ini terdapat pola dengan bentuk bell yang mempresentasikan bahwa pada pola tersebut memiliki stacking pattern berupa retrograding yang menandakan give up carbonates. Hal ini menandakan bahwa karbonat berhenti tumbuh hal ini dikarenakan pertumbuhan muka air laut relatif naik secara tiba - tiba, sehingga mengganggu pertumbuhan karbonat. Hasil analisis elektrofasies pada sumur penelitian terlihat pada Gambar 10.

Penentuan lingkungan pengendapan juga didukung dengan data analisis petrografi, berdasarkan dari analisis petrografi pada setiap sampel, didapatkan bahwa batuanya pada penelitian ini telah terubahkan yang dibuktikan dengan tidak terlihat dengan jelas struktur awal batuan dan pada batuan tersebut mengalami proses dolomitisasi. Selain itu pada analisis nya terdapat porositas intercrystalin dan vuggy.

Berdasarkan hal tersebut menunjukkan terdapat proses diagenesis marine freatic, mixing dan meteroic vadose (Longman, 1980 dalam Tucker dan Wright, 1990).Adanya proses tersebut menunjukkan bahwa batuan tersebut terendaptkan pada lingkungan intertidal dengan lingkungan pengedapan berupa lagoon yang mempunyai ciri khas terjadinya proses dolomitisasi dan keterdapatan mikrit. 


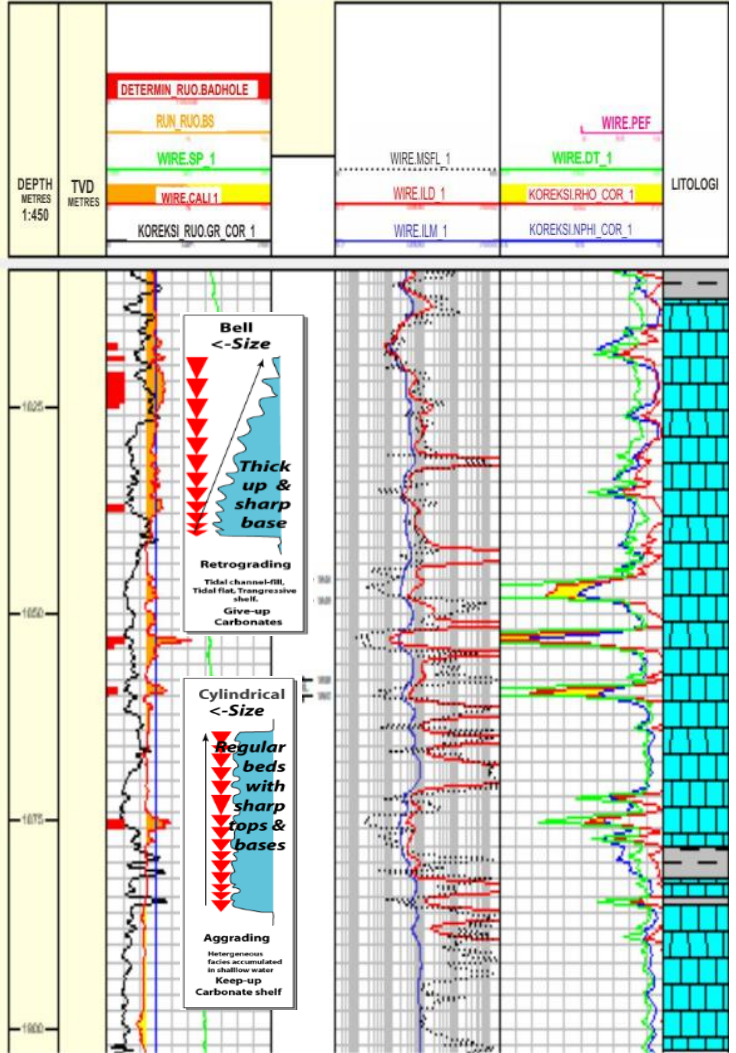

Gambar 10 Analisis Elektrofasies Sumur RUO 31 terdapat bell shape (indikasi retrogradasi) dan cylindrical (indikasi agradasi), diinterpretasikan sebagai keep up dan give up carbonate.

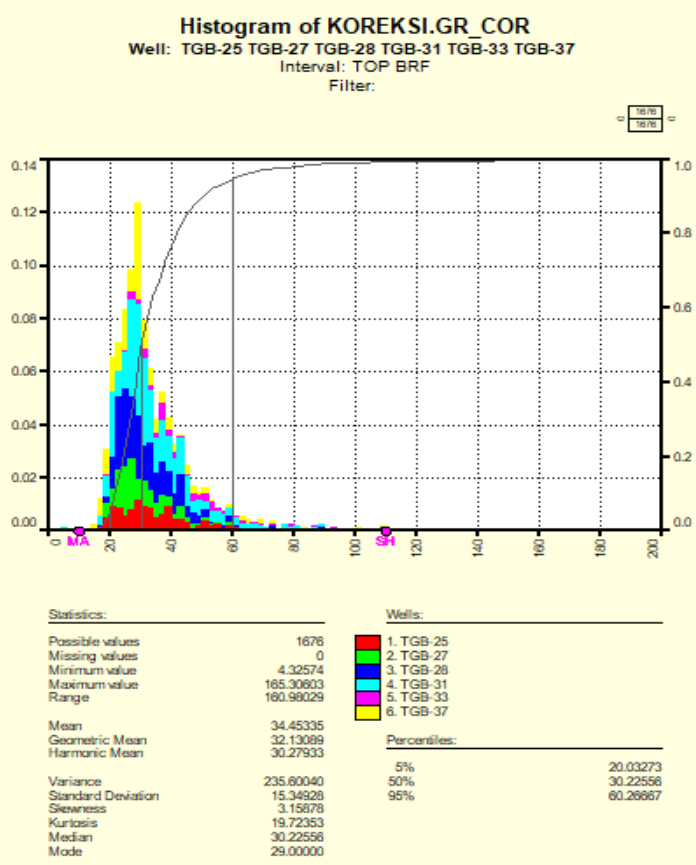

Gambar 11. Histogram Gamma Ray dalam Penentuan Nilai MA dan SH
Rentang batimetri lingkungan intertidal terletak antara pasang rata-rata tertinggi dan terendah, dimana perubahan teratur antara pasang dan surut terjadi, selain itu pada lingkungan pengendapan ini merupakan zona untuk terjadinya alterasi diagenetik awal, termasuk dalam pembentukan dolomit dan evaporit, hal ini sejalan dengan analisis petrografi dan kandungan mineral yang terdapat pada percontoh sampel batuan yang didominasi oleh adanya mineral dolomit sekitar 95\% dari seluruh sampel. Diinterpretasikan bahwa pada batuan tersebut mengalami proses dolomitisasi.

\section{Analisis Petrofisik}

a. Volume Shale

Persamaan 1 dan 2 menunjukkan bahwa data yang harus dipenuhi adalah GR log, GR min dan GR max. Data ini didapatkan dari log gamma ray yang nantinya dituangkan kedalam bentuk histogram untuk dapat menentukan nilai SH (GR max) dan nilai MA (GR min). Didapatkan bahwa nilai MA 10 dan nilai SH 110 (Gambar 11). Nilai ini akan diinput kedalaman perhitungan menggunakan software, sehingga didapatkan volume shale 0,24281 untuk rata - rata disemua sumur selain itu output dari perhitungan ini berupa log. Nilai volume shale yang didapatkan dikategorikan dalam nilai yang kecil. Semakin kecil kandungan shale pada suatu batuan semakin baik begitu sebaliknya. Jika kandungan shale besar maka ini akan merugikan hal ini dikarenakan shale bersifat impermeabel yang nantinya berpengaruh terehadap porositas batuan. Dalam penentuan zona reservoir kandungan shale sangat diperhatikan.

b. Perhitungan Porositas

Penentuan porositas juga berpengaruh terhadap penentuan zona reservoir. Penentuan zona reservoir tersebut diambil dari nilai porositas yang besar agar semakin banyak fluida yang dapat disimpan oleh batuan. Porositas yang perlu diperhatikan adalah porositas efektif, yaitu pori pada batuan yang memiliki kesinambungan dengan pori yang lain dalam satu tubuh batuan. Porositas pada setiap sumur dapat dilihat pada Tabel 1. Porositas efektif rata-rata Formasi Baturaja ini berkisar $4-6 \%$, dikategorikan buruk (poor). 
Tabel 1. Nilai Porositas Efektif Formasi Baturaja di Lapangan Aulia

\begin{tabular}{cccc}
\hline \multirow{2}{*}{ Well } & \multicolumn{3}{c}{ Porositas Efektif $(\%)$} \\
& Min & Max & Average $(\%)$ \\
\hline RUO 25 & 0 & 26,70 & 5,22 \\
RUO 27 & 0 & 27,19 & 6,55 \\
RUO 28 & 0 & 25,21 & 4,05 \\
RUO 31 & 0 & 27,96 & 3,84 \\
RUO 33 & 0 & 18,46 & 1,34 \\
RUO 37 & 0 & 26,90 & 4,11 \\
\hline
\end{tabular}

Tabel 2. Hasil Analisis Permeabilitas

\begin{tabular}{cccc}
\hline \multirow{2}{*}{ Well } & \multicolumn{3}{c}{ Permeabilitas (mD) } \\
& Min & Max & Average \\
\hline RUO 25 & 0 & 34,7473 & 2,0452 \\
RUO 27 & 0 & 37,3864 & 2,0120 \\
RUO 28 & 0 & 27,6017 & 1,3992 \\
RUO 31 & 0 & 41,7776 & 1,9008 \\
RUO 33 & 0 & 7,9379 & 0,0134 \\
RUO 37 & 0 & 35,8055 & 0,8759 \\
\hline
\end{tabular}

c. Perhitungan Permeabilitas

Hasil perhitungan disajikan pada Tabel 2 dan permeabilitas pada daerah penelitian tergolong tight dimana rata - rata nilai yang didapatkan dalam analisis pada masing masing sumur berkisar $0,0134-2,0452 \mathrm{mD}$ (Tabel 2.) kecilnya nilai dari permeabilitas dipengaruhi oleh besaran nilai porositas efektif dari suatu batuan, dimana hubungan antara keduanya berbanding lurus. Semakin besar porositas efektif suatu batuan maka permeabilitas batuan juga semakin besar.

\section{Pay Summary}

Perhitungan nilai penggalan nantinya akan memilah data dari data reservoir yang akan dihitung ketebalannya. Tujuan dilakukannya pay summary ini untuk mendapatkan informasi ketebalan gross, net dan hasil netpay pada zona reservoir yang telah ditentukan. Thickness gross menggambarkan penyebaran tebal tipisnya lapisan yang tidak berhubungan dengan ketinggian atau kedalaman. Thickness net menggambarkan suatu akumulasi dari ketebalan hidrokarbon yang sudah tidak terakumulasi dengan pengotor seperti batulempung dan sebagainya yang ada dalam suatu lapisan serta tidak berhubungan dengan ketinggian. Rangkuman hasil pay sum dari semua sumur terlihat pada lampiran

Pada sumur RUO 25 memiliki net reservoir sebesar 3,5 m dengan net pay sebear $3,5 \mathrm{~m}$. Sumur RUO 27 memiliki net reservoir sebesar
2,5 $\mathrm{m}$ dengan net pay sebesar $2 \mathrm{~m}$. Sumur RUO 28 memiliki net reservoir $3,5 \mathrm{~m}$ dengan net pay sebesar 3,5 m dan sumur RUO 37 memiliki net reservoir sebesar $1,5 \mathrm{~m}$ dengan net pay sebesar $1,5 \mathrm{~m}$. Nilai net reservoir dan net pay yang paling besar dari keempat sumur tersebut yaitu pada sumur RUO 25 dan RUO 28 yang memiliki ketebalan yang lebih tebal dibandingkan dengan sumur lainnya. Sehingga dengan tebal nya net reservoir maka kandungan hidrokarbon yang terdapat pada lapisan reservoir pada RUO 25 dan RUO 28 berbanding lurus dengan ketebalan yang dimiliki.

\section{KESIMPULAN}

Lapangan Aulia tersusun dari batugamping dan batulempung. Jenis batugamping pada penelitiannya adalah packstone - wackestone, shale dan dolomite. Batuan ini terbentuk pada lingkungan pengendapan laut dangkal yaitu intertidal dengan fasies terumbu yaitu fore slope sampai front reef. Volume shale sebesar $0,24281 \mathrm{~V} / \mathrm{V}$, porositas efektif sebesar 0,04305 $\%$, saturasi air 0,69432 dan permeabilitas $1,56791 \mathrm{mD}$. Zona reservoir prosepektif pada sumur RUO 25 pada kedalaman $1.846-1.849 \mathrm{~m}$ dan 1.854 - $1.860 \mathrm{~m}$, sumur RUO 27 pada kedalaman $1.932-1.934 \mathrm{~m}$ dan $1.951-1.954 \mathrm{~m}$, sumur RUO 28 pada kedalaman $1.950-1.952 \mathrm{~m}$ dan 1.955 - $1.958 \mathrm{~m}$, sumur RUO 37 pada kedalaman $1.987-1.988 \mathrm{~m}$ dan $2.010-2.014 \mathrm{~m}$.

\section{UCAPAN TERIMA KASIH}

Penulis bermaksud mengucapkan terima kasih kepada

\section{DAFTAR PUSTAKA}

Asquith, G. dan Gibson, C., 1983. Basic Well Log Analysis for Geologist, Oklahoma : The American Association of Petroleum Geologist.

Freidman, G. M., dan Reeckmann, A., 1982. Exploration For Carbonate Petroleum Reservoirs, Department of Geology, Rensselaer Polytechnic Institute, New York

Harsono, A., 1997. Evaluasi Formasi dan Aplikasi Log, Schlumberger Oilfield Services, Jakarta.

James, N.P., dan Macintyre, I.G., 1985, Carbonate Depositional EnviromentsModern and Ancient Part 1 Reef - Zonation, Depositional Facies, Diagenesis. Colorado School Mines Quarterly, Colorado, 
Researchgate,

doi:

10.1017/S0016756800034968.

Kendall, G.S.C. dan Schlager, W.,1981, Carbonate and Relative Changes in Sea Level, United States of America, Gulf Research Company

Koesoemadinata, R. P., 1980, Geologi Minyak dan Gas Bumi Edisi Kedua. Institut Teknologi Bandung. Bandung

Noble, R.A., Hehu P., dan Charlie Wu, C.H. 1997. Oil Kitchen and Petroleum Bearing Subbasin in Northwest Java Area, Proceedings of Indonesian Petroleum Association, 26th Annual Convention, Jakarta.

Pertamina, 1996. Petroleum Geology of Indonesian Basin Volume III: West Java Sea Basin, Pertamina BPPKA

Pettijohn, F.J., 1975. Sedimentary Rock, 3rd edition, Harper dan Row Publishing Co., New York, $628 h$.

Sibley, D.F. dan Gregg, J.M., 1987. Classification of Dolomite Rock Texture, Journal of Sedimentary Petrology. P.967-975

Tucker, M. E., dan Wright, P., 1990, Carbonate Sedimentology, Oxford, Blackwell Scientific Publication

Wahab, A. dan Martono, D., 1985. Aplication of Oil Geochemistry for Hydrocarbon Exploration in Nothwest Java, Semantic Scholar, 41, $513-521, \quad$ doi: 10.29118/ipa.256.657.682.

Walker, R.G., dan James, N.P., 1992. Facies Models Response to Sea Level Change, Canada: Geological Association of Canada. 
